Leonid Zhelezny, Yevgen Kobylyansky and Oleg Mishchuk

\title{
INFLUENCE OF THE NATURE OF A DISPERSED PHASE ON ANTIWEAR PROPERTIES OF HIGH TEM PERATURE GREASES
}

\author{
Ukrainian Scientific and Research Institute for Oil Refining Industry "MASMA" \\ 46, Palladin avn., Kyiv - 142, 03680, Ukraine \\ masma@svitonline.com
}

Received: May 16, 2007

\begin{abstract}
Antiwear properties of modern high temperature greases have been studied by simulating various temperature and load conditions on friction machines. Differences in tribological characteristics of greases depending on the nature of their thickeners were determined and explained. Maximum antiwear properties were revealed in conventional complex and overbased complex calcium salicylate, sulfonate and phenolate greases.
\end{abstract}

Key words: high temperature greases, dispersed phase, dispersion medium, antiwear properties, wear scar diameter.

\section{Introduction}

The main function of antifriction greases is the prolongation of the service life of machines and mechanisms at the cost of friction and wear reduction of their moving parts and the elimination of seizure and jamming processes of conjugated friction surfaces. Despite a great number of works devoted to the research of tribological properties of lubricating materials, the generalizations pertaining to the influence of a dispersion medium and thickener upon lubricating ability of various types of greases are not quite sufficient and those given in the available literature sources are very often contradictory [1,2]. Intensive scientific studies in this field were performed in 60-80-ties of the past century. Lithium, sodium, hydrated and complex calcium greases as well as some greases based on organic and inorganic thickeners were the main objects of research in those years. Tribological properties of greases were researched mostly with the purpose of selecting the optimal composition of additives. The lubricating ability of basic greases was not practically studied in spite of the fact that many general purpose greases even without antiwear and extreme pressure additives in their composition are capable of providing the normal work of friction units within certain ranges of speeds and loads.
The possibility of formation of boundary lubricating films and their influence on mechanical and chemical conversions of a friction surface were proved by numerous scientific works which were the basis of modern ideas of friction, wear and lubrication [3, 4]. It was found out that a lubricating ability is a complex function of composition, structure and physico-chemical properties of greases and friction surfaces. Structurized spatial structure of greases with specific bulk and mechanical properties as well as the presence of different surface active substances in their composition has given the grounds to consider that lubrication action is connected with bulk and adsorptive, in particular, hemisorption actions.

In recent years the assortment of antifriction greases has been considerably extended and now the market of lubricating greases is represented with a number of high temperature products with diverse spectrum of thickeners used. Due to broadening of a temperature range, the increase of speeds and loads in operating equipment, the enhancement of its power and capacity and, consequently, with growing hard requirements for lubricating materials, it is exactly high temperature greases (with dropping point not less than $503 \mathrm{~K}$ ) are playing the leading roles both in production volumes and in application. Proper selection of such greases, their effective and rational use allows to substantially lower the energy consumption bringing about a significant economy of power.

\section{Experimental}

In the proposed work, it the lubricating ability of the most widespread high temperature greases has been investigated with the purpose of determining the connection between the nature of a dispersed phase and tribological characteristics of a dispersion medium (petroleum oil) thickened by it as well as to find out the most effective thickeners. Complex soap greases which have been thickened by anionically complex soaps representing by themselves either adsorptive or molecular 
complex of soap of higher fatty acid and salts of low molecular organic or mineral acids and also greases based on highly dispersed modified silicon oxide (pyrogenic silica gel or aerosile), organo-substituted mineral (bentonite), urea derivatives, complex overbased calcium sulfonates, salicylates and phenolates have been tested.

All samples of greases were prepared in accordance with the energy saving technologies making it possible to optimize the temperature regime of greases preparation, to reduce the number of stages of a technological process and to significantly decrease a production cycle. Petroleum oil containing $72.0 \%$ of mass paraffino-naphthenic hydrocarbons, $21.6 \%$ of light and $4.7 \%$ of middle aromatics as well as $1.7 \%$ of resins have been used as the dispersion medium for greases. The penetration index of model grease samples was equal to $265 \pm 5$ m" $10^{-4}$ (GOST 5346), the dropping point - 503-543 K (GOST 7693 , for greases on aerosile and bentonite such index is not available), the content of free alkalis in complex soap greases in conversion to $\mathrm{NaOH}-0.1-0.2 \%$ (GOST 6707), the base number of overbased greases $\sim 250 \mathrm{mg} \mathrm{KOH} / \mathrm{g}$.

The ability of petroleum oil and greases to reduce wear over the range of loads $392-748 \mathrm{~N}$ on its basis have been evaluated in four ball friction machine at $293 \mathrm{~K}$ according to GOST 9490. Wear scar diameters $\left(D_{i}\right)$ of modal systems at higher (elevated) temperatures have been determined after ASTM D 226 in Falex four ball friction machine (load $-392 \mathrm{~N}$, frequency of rotations -1200 $\left.\min ^{-1}\right)$. At this point it is necessary to consider the following. It is well-known [5] that the structure of SHkH-
15 steel of which the balls of a friction pair are made, is changed within the range of temperatures from 353 to $523 \mathrm{~K}$. This results in inhomogeneous micro scratching produced with wear particles during friction at elevated temperatures on the surfaces of steel balls (scoring). Micro scratches can appear in a compression zone far away beyond the friction zone limits and should not be considered during evaluation of a wear scar diameter. Otherwise this can be the reason of significant errors in experimental data.

\section{Results and Discussion}

Antiwear action of greases in four ball friction machine is provided mainly due to the formation of a boundary lubricating film on a metal surface $(\sim 1 \mathrm{mkm})$ with a large number of molecular layers, the anisotropy of mechanical properties, high resistance to great normal loads and low - to the action of circumferential stresses as is also due to the chemical conversions on a friction surface [4]. Wear of a friction surface at $196 \mathrm{~N}$ and $293 \mathrm{~K}$, as it is proved by the data presented in the Table, is negligible and a friction process depends to a small degree upon the nature, polarity and chemical activity of the components of a grease thickener. Higher antiwear properties of base oil can be explained by a high rate of oxygen diffusion to a friction surface because of the lower viscosity of oil in comparison with greases and the subsequent formation of active oxygen-containing compounds preventing the wear.

Table

Antiwear properties of high temperature greases

\begin{tabular}{|c|c|c|c|c|c|}
\hline \multirow[t]{2}{*}{ Type of thickener } & \multicolumn{5}{|c|}{$\begin{array}{c}\text { Wear scar diameter }(\boldsymbol{m m}) \\
\text { Steel-steel. } 1 \text { hour. temperature } \boldsymbol{T}(K) \text {. load } \boldsymbol{P}(\mathrm{N}) . \boldsymbol{T} / \boldsymbol{P}\end{array}$} \\
\hline & $293 / 196$ & $293 / 392$ & $293 / 784$ & $373 / 392$ & $423 / 392$ \\
\hline Base oil without thickener & 0.28 & 0.64 & 2.80 & 0.81 & 0.76 \\
\hline \multicolumn{6}{|l|}{ Inorganic } \\
\hline Bentonite & 0.76 & 0.80 & 1.68 & 0.90 & 0.80 \\
\hline Aerosile & 0.53 & 1.15 & 1.64 & 0.83 & 1.11 \\
\hline \multicolumn{6}{|l|}{ Organic } \\
\hline Polyurea & 0.31 & 0.52 & 1.85 & 0.54 & 0.62 \\
\hline \multicolumn{6}{|l|}{ Complex soap } \\
\hline Aluminum & 0.50 & 0.78 & 2.49 & 0.73 & 0.94 \\
\hline Barium & 0.53 & 0.67 & 1.60 & 0.74 & 1.73 \\
\hline Calcium & 0.31 & 0.55 & 0.98 & 0.56 & 0.55 \\
\hline Lithium & 0.43 & 0.50 & 1.55 & 0.49 & 0.73 \\
\hline Sodium & 0.59 & 0.64 & 1.89 & 0.86 & 0.65 \\
\hline \multicolumn{6}{|l|}{ Complex overbased } \\
\hline Salicylate & 0.40 & 0.55 & 0.99 & 0.50 & 0.56 \\
\hline Sulfonate & 0.29 & 0.56 & 1.12 & 0.55 & 0.46 \\
\hline Phenolate & 0.38 & 0.64 & 1.01 & 0.50 & 0.64 \\
\hline
\end{tabular}


A physico-chemical activity of greases in the process of friction, that is, kinetics of the interaction of active grease components with metal surface and the relationship between the rate of a strong boundary film formation or mechano-chemically modified surface layer and their destruction gained in importance when increasing loads in our experiments from 196 up to $748 \mathrm{~N}$. At the maximum load $(784 \mathrm{~N})$, as it is evident from the data presented in the Table given below, the antiwear action of all greases is much superior to the analogical index of their dispersion medium - petroleum oil. Since the composition of greases contains surface active substances - elements of a thickener and technological surfactants (TSA), precisely their polarity, dimensions and structure of molecules determine the adsorptive activity and, in the end, the strength of boundary layer and the ability to deform a surface layer of metal.

At the load of $392 \mathrm{~N}$, most thickeners improve antiwear properties of a dispersion medium. Polyurea or urea (Ur-) grease and lithium complex grease are characterized by the minimum " $\mathrm{D}_{i}$ " which is equal to 0.50 $\mathrm{mm}$. For some modal samples, however, thickening of oil with certain complex thickeners does not influence on the lubricating ability of the initial dispersion medium, since the structure of greases is destroyed at normal shearing stresses in a friction zone. Complex aluminum (cAL-) aswell as inorganic thickeners such as bentonite (Bn-) and especially aerosile ( $\mathrm{Si}-)$ enhance " $\mathrm{D}_{i}$ " of petroleum oil. It should be pointed out that aluminum complex greases are produced on practically nonpolar di-substituted aluminum soap of stearic and benzoic acids which soap forms complex branching polymer like structure due to the coordination bonds between aluminum atoms of one molecule and oxygen atoms of a hydroxyl group of the other molecule of soap. As it is shown in [6], lowering of the polarity of soap molecules reduces the lubricating ability of greases based on petroleum dispersion media.

Si-grease, one of the objects of our research, has been produced on aerosile modified with dimethyldichlorinesiloxane (DMDCS). As a result of modification, active centers of an aerosile surface are excluded from interaction, the forces acting between particles of the thickener as well as between the thickener and the dispersion medium of grease are weakened [1]. Besides, in the process of friction at high contact loads, the destruction of a boundary and modified layers, probably, goes faster due to the weakness and instability of interaction forces between the particles of aerosile and a steel surface. The same regularities are evidently habitual to Bn-grease being under friction and above-mentioned loads.

It was prepared on bentonite and modified with dimethyldioctadecylammonium -chloride which is known under the trade mark "Bentone-34". The thickener has a strongly developed micro porous structure with adsorbed molecules of a modifier on the surface. However, on increasing the severity of friction regimes, the surface activity of surfactants (SAS) desorbed from particles of a mineral and TSAS present in the grease turns out to be insufficient to form a strong and stable boundary layer of grease on a metal surface.

A sharp increase in " $\mathrm{D}$ " is observed for Ur-grease as loads growing higher. In order to understand the reasons of this phenomenon it is necessary to consider the structure of polyurea thickener. Depending on amines (aliphatic, cyclic or aromatic) used for its preparation, their ratio as well as temperature conditions during grease production, a dispersed phase in a petroleum oil can acquire a great variety of structural forms and the grease by itself will significantly differ just in mechanical, colloid and thermal stabilities as well as in high temperature properties and lubricating ability. It is pointed out in the work [7] that the presence of aryl amines in the composition of polyurea thickener substantially enhances performance characteristics of the grease and makes a positive effect on the thickness and load carrying capacity of a lubricating layer. For research studies, we have prepared a modal sample of Ur-grease with balanced properties but that required lowering the content of aromatic amine in the thickener's composition. The strength of a boundary lubricating film on a steel surface at friction was decreased that resulted in the significant rise of " $\mathrm{D}_{i}$ " value at the load of $784 \mathrm{~N}$.

The strongest films on a steel surface are formed under the influence of calcium complex greases (both conventional $\mathrm{cCa}-$ and all three overbased calcium: sulfonate ( $\mathrm{Su}$-), alkylsalicylate (As -) and phenolate (Fn -). Their " $\mathrm{D}_{i}$ " at maximum load $784 \mathrm{~N}$ are three times less than in a petroleum oil. It is likely that calcium hydroxide plays an important role in forming a boundary layer. In cCa-grease, calcium hydroxide is present in a free form and is also connected coordinationally with the structural skeleton of cCa-grease which is formed by a complicated calcium complex consisting of stearic and acetic acids. $\mathrm{Ca}(\mathrm{OH})_{2}$ if compared with other alkalies, is less active, moreover, higher degree of alkalies bonding by cCa-grease due to the enhanced ability to form adsorptive complexes [1] leads to minimum chemical conversions of friction surface and the preservation of its initial strength. Authors $[8,9]$ explain the formation of complex calcium grease of highly strong boundary layer that prevents wear of friction surfaces at high loads as a result of calcite polymorphic modification in carbonate nuclei of micellae - the main cell of the structural skeleton of these greases. Nano-sized petals of calcite of overbased sulfonate due to the significant value of ratio of a surface area to volume have an enormous surface activity owing to which they are oriented in a lubricating film with the definite manner forming a peculiar covering like fish scales and take an 
active part in tribo-chemical conversions of surface layers.A particular role is played by the constituents of the overbased component of sulfonate complex grease, namely, calcium metaborate being a part of micelle's nucleus and calcium 12-hydroxy stearate forming together with calcium sulfonate the adsorptive envelope of grease.

Molecules of calcium metaborate loosens nuclei of micellae, thus, intensifying the surface activity of calcite due to increased defects of its particles' surfaces and, in this manner, facilitating the access of molecules of sulfonate and calcium 12-hydroxy stearate to a metal surface. A similar mechanism of a lubricating action is probably typical of complex As- and Fn- greases [10].

On rising the temperature in a friction zone from 293 up to $423 \mathrm{~K}$, the role of surfactants desorption process from a surface friction as well as the chemical constituent in the interaction process of the active components of grease and a metal surface is growing in importance. Moreover, the influence of oxygen on the processes of boundary friction is enhanced. In this case it is suggested [6] that oxygen presence and high temperatures are beneficial to the intensive oxidation of a friction surface and, consequently, to raising the adsorption of polar ingredients contained in grease. At the same time, the oxidation of a dispersion medium takes place, primarily, naphthenes and light aromatics as well as other components of grease and that results in rising of their surface activity. It is suggested that chemically active components of petroleum oil formed at high temperatures can interact with a metal surface and make a sufficiently strong film in order to withstand the load of $392 \mathrm{~N}$ and to prevent a wear. Therefore, " $\mathrm{D}_{i}$ " of a dispersion medium within the range from 293 to $423 \mathrm{~K}$ is grown approximately by $0.15 \mathrm{~mm}$ only (see Table).

On increasing the depth of the oxidation of greases, the deterioration of their antiwear properties becomes appreciably evident. It is pointed out in a number of works $[1,6]$ that there is a correlation between thermal oxidation stability of some soap greases and their lubricating ability.

The data of the Table indicate that elevated temperatures have particularly adverse effect on the lubricating ability of Barium complex grease (cBr-). Within the temperature range of 293-373 K, surfactants desorption and chemical interaction of the components of grease with steel do not promote a substantial rise of " $\mathrm{D}$ " index.

At $423 \mathrm{~K}$, however, the lubricating action of a boundary layer is changed with a seizure due to the intensification of oxidation processes, the destruction of a lubricating film and the sharp activation of chemical transformations. This causes the growth of " $D$ " index to the maximum value $(1.73 \mathrm{~mm})$ amid all studied modal greases at this temperature including their dispersion medium $(0.76 \mathrm{~mm})$. It is conceivable that $\mathrm{cBr}$-grease is the most stable to oxidation because of the initiating action of soaps and salts of acetic acid; this action manifests itself after the complex thickener's destruction. Similar to cBr-grease, the growth of " $\mathrm{D}_{i}$ " index for $\mathrm{cAl}-, \mathrm{cLi}$ - and Ur-greases with rising temperature is observed, but not in such sharp form (see Table). This is likely to be connected with the different thermal stability of films, the different ability of greases to adhesion under these conditions as well as their diverse stability to oxidation.

The rising of " $\mathrm{D}_{i}$ " for 0.24 and $0.10 \mathrm{~mm}$, respectively, is characteristic of $\mathrm{kNa}$ - and $\mathrm{Bn}$ - greases at $373 \mathrm{~K}$ in comparison with the same index at 293 and $423 \mathrm{~K}$ (see Table). It is obvious that due to the differences in nature, polarity and other characteristics of the thickeners of these greases, the mechanism of their lubricating action causing such anomalies is cardinally different. It can be suggested that antiwear properties of $\mathrm{kNa}$-grease at $373 \mathrm{~K}$ are decreased because of the destruction of an adsorptive layer on a metal, the weakening of bonds in $\mathrm{kNa}$-thickener and the intensification of oxidation, that is brought about, among other things, by the induced action of sodium salts of various acids uncombined in a complex and as for the high temperature effect it is still insufficient for the intensive chemical interaction of components of grease, both present in it primordially and those newly formed, with a metal surface producing new products which form the strong boundary layer.

At temperature of $423 \mathrm{~K}$, generated oxygen-containing surfactants together with other substances having high reactivity probably are capable of forming a stable lubricating hemisorptive film which is by its strength in no way inferior to that formed at $293 \mathrm{~K}$ but formed according to other mechanism. Deterioration of $\mathrm{Bn}$-grease antiwear properties at $373 \mathrm{~K}$ is induced, possibly, by the desorption of bimolecular layer of organic cations from the surface of bentonite, that is molecularly combined modifier, the redistribution of the molecules of surfactants on the surface of thickener and metal, and, caused by these processes, the destruction of a lubricating film. It can be also assumed that stabilization of a system and " $\mathrm{D}_{i}$ " reduction at $423 \mathrm{~K}$ is takeing place as the consequence of adsorption of products of thermo chemical and thermo oxidation changes of a dispersion medium on the surfaces of bentonite's particles and, especially, on the surface of steel; all this results in the transformation of a metal surface itself.

Conservation of antiwear properties on one and the same level within a wide range of temperatures of Sigrease on aerosile with a high degree of modification is caused by thermostability of the grease as such and conditioned by the nature of the adsorptive boundary layer formed on a mineral. However, the possibility of DMDCS molecules destruction with the following chlorine penetration in a friction zone is not excluded under high temperatures. This active element, under certain conditions, can improve antiwear indices chemically polishing friction surfaces, evenly distributing loads and, thus, reducing local 
temperatures and pressures [6]. It is quite possible that the decrease, to some extent, of Si-grease's " $D$ " index at $373 \mathrm{~K}$ is connected with the realization of the above mentioned mechanism.

Antiwear properties of cCa-grease and overbased calcium greases do not practically change within the studied range of temperatures and remain very high ( " $\mathrm{D}_{\mathrm{i}}$ " $\sim 0.55 \mathrm{~mm}$ ). This affirms the efficiency of lubricating and, probably, antioxidation action of the thickener's components of these greases, their capability to different types of sorption and the interaction with metal surface under high temperatures due to the availability of sufficient quantity of active functional groups.

\section{Conclusion}

Thus, to protect steel surfaces under friction against wear within a wide range of temperatures and loads under conditions when other properties of general purpose greases without antiwear and extreme pressure additives are not so important, it is expedient to use conventional complex (with periodical change of grease in a friction unit) or overbased complex calcium salicylate, sulfonate and phenolate greases (when grease is packed for the whole service life of a friction unit).

\section{References}

[1] Ishchuk Yu.L.: Composition, Structure and Properties of Lubricating Greases. Kyiv, 1996.

[2] Klamann D.K.: Greases and Related Products. Moskwa, 1984.
[3] Boden F.P. and Tabor D.: Friction and Lubrication of Solid Bodies. Moskwa, 1968.

[4] Kostetsky B.I.: Surface Strength of Materials under Friction. Kyiv, 1974.

[5] Blanter M.E.: Theory of Thermal Treatment. Moskwa, 1984. [6] Fuks I.G. : Additives for Lubricating Greases. Moskwa, 1982.

[7] Mitsuoka M., Nakajima Y., Miyamoto Y. and Iwamatsu H.: NLGI Spokesman, 2003, 5, 22.

[8] Hunt M.W.: Lubricating Engineering, 1975, 31, 183.

[9] Makedonsky O., Kobylyansky E. and Ishchuk Yu.: Eurogrease, 2003, 5, 5.

[10] Papeykin O.O., Kobylyansky E.V., Zhelezny L.V., Kravchenko O.R. and Ishchuk Yu.L.: Lubes'n'Greases, 2006, 12, 44.

\section{ВПЛИВ ПРИРОДИ ДИСПЕРСНОЇ ФАЗИ НА ПРОТИЗНОШУВАЛЬНІ ВЛАСТИВОСТІ ВИСОКОТЕМПЕРАТУРНИХ МАСТИЛ}

Анотація. Вивчались протизночувальні властивості сучасних високотемпературних мастил моделюванням на машинах тертя при різних температурах та навантаженнях. Встановлена та пояснена різниця у трибологічних характеристиках мастил в залежності від природи їх загусника. Максимальні протизношувальні властивості виявлено у звичайних комплексних і комплексних надлужних саліцилатних, сульфонатних та фенолятних кальцієвих мастилах.

Ключові слова: високотемпературні мастила, дисперсна фаза, дисперсне середовище, протизношувальні властивості, діаметр плями зношування. 